\title{
Who Should Interview Older People? The Effect of Interviewer and Interviewee Characteristics in Surveys of Older People and Aging Topics ${ }^{1}$
}

\author{
Lucie Vidovićová ${ }^{2}-$ Tomáš Doseděl ${ }^{3}$ \\ Office for Population Studies, Faculty of Social Studies, Masaryk University, \\ Brno
}

Who Should Interview Older People? The Effect of Interviewer and Interviewee Characteristics in Surveys of Older People and Aging Topics. Objectives: Aging of the population has increased the need to gain a better understanding of older people's experiences, especially by collecting their views on various issues and quantitative surveys are frequently used methods.

Methods: Five hypotheses are presented on assumption that the characteristics of the respondent and the characteristics of the interviewer (age and gender) significantly affect the interviewer's perceived difficulty in conducting the interview with respondents in higher age on aging related topics. Pooled data from seven quantitative surveys are used to test these hypotheses with multi-level linear regression.

Results: Results show that age of interviewers increases the perceived difficulty only slightly if we control for the influence of the gender of the interviewer and the respondent's age and education. Also, more positively aging respondents make the interviews about aging topic easier for interviewers. These influences vary in each of the survey projects and topic.

Discussion: Age- and gender-sensitive training and supervision when age/gender sensitive topics are to be surveyed is, according to our results here, strongly advisable.

Sociológia 2018, Vol. 50 (No. 6: 760-781)

https://doi.org/10.31577/sociologia.2018.50.6.28

Key words: Survey methodology; interview difficulty; research interview; multi-study; interviewer; morale; gender mismatch; age mismatch

Motto: There is no such thing as an ideal interview

(Benney et al. 1956)

\section{Introduction}

The increasing number and share of older people in western societies has increased also the need to gain a better understanding of older people's experiences, especially by collecting their views, opinions, and stand points on various issues. Although the variety of approaches and methods used in

\footnotetext{
1 This work was supported by the Czech Scientific Foundation projects "Rural Ageing: unanswered question(s) of social gerontology" (GA16-20873S) and "Fourth Age: Identity of Disability in the Time of Active Ageing" (GA15-03156S). The data collection of "Ageism 2003" and "Consumption and Consumers in Higher Age 2011" surveys was supported by the Research Institute for Labour and Social Affairs (RILSA). The authors would like to thank to the three anonymous reviewers for their valuable comments and to Matthew Nicholls for language editing.

2 Address: Mgr. Lucie Vidovićová, Ph.D., Office for Population Study, Faculty of Social Studies, Joštova 10, 60200 Brno, Czech Republic. E-mail: vidovicova@fss.muni.cz

3 Address: Mgr. Ing. Tomáš Doseděl, Office for Population Study, Faculty of Social Studies, Joštova 10, 60200 Brno, Czech Republic. E-mail: dotomas@mail.muni.cz
} 
research into older populations is widening, quantitative surveys remain among the most frequently used methods. This could be for various reasons besides the obvious scientific one - in particular, the social, or socio-political, demand for quantifiable and aggregated data to support better policy making within aging societies (Recommendations 2016), and for the purposes of marketing in the commercial sphere. Either way, we argue that insufficient attention has been paid to the quantitative methodology of the survey with respect to older populations in general, and to the interview situation involving interviewers and older respondents in particular. The pace of methodological innovation in traditional, questionnaire-based interviewing is not keeping step with the dynamic development of interest in the opinions and experiences of the older population. While there has been a real revolution in the usage of technologies to assist in the collection, recording, and analysis of survey data, very little knowledge has been collected since the 1980s (cf. Weil 2015; 2017) on the (at least so far) omni-present human factor in communication flow and information exchange in the survey context - even less so if the exchange involves an older person as a research subject and aging experience as a research topic. With this paper, we aim to fill this gap.

In the routine use of survey data, scientists working in a quantitative paradigm tend to assume that respondents' answers are a valid reflection of the social reality. Any random distortions at the individual level, based on their assumptions, will disappear with larger data sets and the use of inference statistics methods. But what if the bias is systematic in some way, and even statistical generalization does not remove its influence? By means of the secondary analysis of data from seven quantitative surveys conducted in the Czech Republic, we seek to answer the following main research question: What aspects influence the quality of cooperation with the senior respondent in surveys on aging? We present five hypotheses that assume that the characteristics of the respondent (age, gender and education, subjective age, and morale) and the characteristics of the interviewer (age and gender) significantly affect the interviewer's perceived difficulty in conducting the research interview and filling the questionnaire with particular interviewee(s). We came to the conclusion that there is a strong correlation between the characteristics of the interviewers and those of the respondents and that certain values of the paradata will subsequently appear in the data set. This has major implications for the appropriate recruitment of interviewers employed to interview senior citizens and for their training in preparation for projects targeting older populations and aging topics. As Derrett and Colhoun (2011: 9) put it, "interviewers are employed to scientifically gather quantitative data, yet their effectiveness relies largely on their humanity". 
Our study is structured as follows: First, a brief overview of previous findings on this topic is presented (i.e. why and how some groups of older respondents can be more difficult to talk to and what is known about the interviewers' role). Subsequently, hypotheses are formulated, and the data sources, variables and analytical methods used are presented. In the next part the hypotheses are tested and interesting partial results are summarized. The last chapter discusses the results in the wider context of aging studies.

\section{Literature review}

\section{The older respondent}

When the reliability and validity of research instruments (Cleary et al. 1981) or responses on factual questions such as age (Smit et al. 1997) in older adults are scrutinized, the usual concerns are physical and mental health. Special attention has been paid to conducting research with the oldest-old (Isaksson et al. 2007; Willard - Herzog 1995), frail subjects (Peel - Wilson 2008; Gibson Aitkenhead 1983), or people with dementia. (Hess-Wiktor - Opoczyńska 2012) Normal, healthy aging is usually not problematized or discussed. (See exception in Carp 1989; Weil 2017)

The most frequently cited sources of error or misrepresentation include health, sensory and cognitive impairment, and the personality and motivational factors associated with age or cohort. (Rodgers - Herzog 1995) A frequently mentioned subject of methodological debate concentrates on improving the performance of older respondents and the quality of data provided by them. To provide respondents with basic training is suggested, and they are also expected to gain experience in the process of interviewing. This is why Burchell and Marsh (1992) argue that the increased duration of the survey can improve the quality of the data, with the older respondent gaining greater experience as the survey proceeds. The proper balance should be established though, since extending the length of the survey also tends to decrease the quality of the collected data due to fatigue. Moles (1987, in Rodgers - Herzog 1995) reports that the length of the interview and the proportion of respondents who feel tired at the end of the interview increase with age, but Gibson and Aitkenhead (1983), on the other hand, claim that "physical and mental frailty and respondent's fatigue led to few interviewing difficulties. Elderly respondents were found to be somewhat reticent on traditionally "difficult" questions such as income, but no particular problems were encountered with potentially emotional or threatening topics. The main advantages were those associated with high levels of cooperation and interest and few limitations on the time available to respondents to complete the interview". (Gibson - Aitkenhead 1983) The question we will be addressing below is what role these aspects of (/risks in) older respondents play in the course of specific societal/conversa- 
tional exchange in the research interview, and if and how these characteristics of older respondent influence the perceived difficulty of conducting the research on various topics in studies on aging.

\section{The interviewer}

While characteristics of the respondent can be, and many times are, assessed in the course of the survey as such, for the interviewee these are often unknown and unavailable, as he or she is in the employment relation with either the researcher or a hired agency and questions on marital or health status may be regarded as inappropriate and/or discriminatory. (Carp 1989) Yet, as Cleary, Mechanic and Weiss (1981: 183-184) have agreed with many other authors, "the characteristics of interviewers, such as their sex, race, background, attitudes and perceptions affect the responses they elicit... Such effects are not consistent however, but tend to be a function of the interview situation and the specific questions asked (and required is...) a better understanding of the underlying dynamics that lead to distortion in the reporting of both subjective information and objective fact". Boyd and Westfall (1965: 60) suggested that "the more characteristics the interviewer and the respondent have in common the greater the probability of a successful interview", an idea which was later explained as a theory of liking. (Groves et al. 1992) This theory hypothesizes that people with similar attitudes, common interests, or similar characteristics tend to favourably incline to each other, which creates a more favourable atmosphere for the interview, and this in turn establishes a better rapport (Garbarski et al. 2016) and better-quality data. (But cf. Goudy - Potter 1975) The derived homogeneity hypothesis seems to hold particularly for ethnicity (Ghane et al. 2010), education (Durrant et al. 2010), and gender (Vercruyssen et al. 2017), especially with respect to certain survey topics in which these characteristics are relevant and in which a mismatch between interviewer and interviewee may produce a systematic bias. (Huddy et al. 1997; Liu Stainback 2013; Freeman - Butler 1976; Johnson - Delamater 1976; but see Johnson - Moore 1993) In other cases, the results of matching/homogeneity are indecisive. (Davis et al. 2010; Freeman - Butler 1976) We are not aware of any larger study looking at the effects of age mismatch in the context of aging or ageism as a survey subject. (For exceptions with limited survey samples, see Petrová Kafková 2012)

\section{Gender and age}

Gender is the social representation of biological sex and together with age is an immediate source of visual clues in defining social relationships and roles in most of the social contexts covered by communication within a research interview. Hyman (1954: 156) argues that "women interviewers are more competent and more experienced than men interviewers", which may be 
disputable, but according to Freeman and Butler (1976) and many others, men interviewers may solicit different results from women than from men. Benney, Riesman, and Star (1956) found in their inquiry that the age of the interviewer had more effect than his/her sex.

Older interviewers in surveys with older people are usually preferred for at least three reasons: their greater life experience (Hyman 1954; Cleary et al. 1981), their generational closeness as a proxy for mutual understanding; and/or as Kelesey et al. (1989) claims, because many young people are not sufficiently comfortable with the elderly to function as effective interviewers. While the first and last points can be dismissed as ageist, since they take chronological age as a dis/qualification, the hypothesis of generational closeness could be supported by the theory of liking, as already stated above. However, in this context, Rodgers and Herzog (1995: 148) argue that only anecdotal evidence supports the notion that older interviewers might appear less threatening (Cleary et al. 1981) to older respondents, and reduce communication problems across generations. According to Freeman and Butler (1976), older interviewers paired with older respondents produced consistently more interviewer variance than did any other age combination; young-young pairs produced the least. Thus, the expectation that similar age combinations will produce less interviewer variance than different age combinations was not supported. In this study, however, old interviewers were defined as those aged 31 years and older. The concern of Gergen and Back (1966) was that greater age differences between interviewer and respondent may cause the respondent to lose interest in the interview. In contrast, study by Durrant et al. (2010) reported no effect of age on the success of first contact between the interviewer and sample member. As these results are indecisive, we should bear in mind the complexities of both the interviewer's and interviewee's characteristics and their combinations, as well as the general features of the study (methodology, topic, environment, length), all of which could influence the results and should be considered when interpreting them.

\section{Attitudes and personality traits}

Another crucial issue influencing the outcomes of research interviews is the attitudes and personality traits of the interviewers. (Derrett - Colhoun 2011) Appropriate training of interviewers conducting interviews with older respondents is considered of crucial importance, as interviewing some older people, such as frail, with mild cognitive impairments, suffering multimorbidity, etc. may be more stressful than interviewing the general population. (Gibson - Aitkenhead 1983; Hall et al. 2009; de Vries et al. 2014) Such interviews may take longer; older adults are more likely to digress from the topic of the question and are less willing or able to use standardized response 
categories. And, last but not least, "interviews with older persons raise awareness and empathy among the interviewers for problems faced by the aged". (Rodgers - Herzog 1995: 151) Exposure to problems and difficult issues may represent an additional source of distress (cf. Kusumastuti et al. 2017; White 2001), especially if, regardless of the interviewer's own age, his or her attitudes towards old age, older people, and / or aging are inflicted with ageism. (Greenberg et al. 2004)

The rising numbers of older people in the global north and the quest for evidence-based policies have increased the demand for valid and reliable sociological data on various aging topics. As we have seen from the previous argumentation, there are numerous influences which intervene in the communication process, which is crucial part of data collection. These influences are both on the part of the interviewer and of the interviewee and can also be exerted by the research instrument. This is why researchers pay a great deal of attention to research tool design, to the definition of the population, and to methods of sample selection. In many cases, this preparatory process ends with the selection of external cooperants - usually professional agencies dealing with sociological or market research, as many universities, research institutes, municipalities, and other engaged policy stakeholders do not have their own nation-wide network of interviewers in order to be able to carry out their own representative surveys in older populations. In some sense, this brings a black box to the previously highly-controlled process. Professional agencies have various ways to ensure that the interviewers stick to required procedures, observe a code of professional conduct, and are properly trained for any particular job the researcher has designed. However, they remain human, carrying forth their age, gender, and other social characteristics, and their experiences, attitudes, and communication styles in a (usually) unknown "cocktail" of diverse combinations. In the following paragraphs we will try to shed some light on what outcomes in terms of the perceived and recorded ease of interviewing (and potentially data quality) can be expected when controlling for some observable characteristics of the interviewers, and for selected combinations of these characteristics in both the interviewer and interviewee.

\section{Methods}

In order to answer the research question "Which interviewer's and respondent's characteristics influence the quality of cooperation with the respondent?", we formulated the following hypotheses using a review of relevant literature:

H1: Older interviewers record fewer difficulties with filling in questionnaires.

(The hypothesis of the experienced, no threatening interviewer.)

$\mathrm{H} 2$ : Interviewers of the same gender as the respondent record fewer difficulties.

(The hypothesis of homogeneity.) 
H3: Interviewers perceive interviews with respondents with higher levels of education as less difficult. (The hypothesis of the experienced interviewee.) H4: Interviewers perceive interviews with respondents "who age successfully" as less difficult. (The hypothesis of the interviewee not exhibiting the difficulties of advanced age.)

H5: The type of the questionnaire (i.e. number of variables/type of survey/topics covered, etc.) does not influence the recorded ease/difficulty. (The hypothesis of experienced ("professionally detached") interviewer.)

We used data from the seven quantitative surveys conducted in the Czech Republic between 2011 and 2016 under the auspices of projects implemented by the Faculty of Social Studies of Masaryk University and the Research Institute for Labour and Social Affairs. Field data collection was conducted in all cases by specialized social research and market research agencies, with their own interviewee networks. A guarantee that the ESOMAR standards would be observed was required before cooperation was established. This, together with the narrow thematic scope (all studies were looking at various aspects of aging), common leadership and design of the projects as well as of the questionnaires, and the usage of comparable and standardised sets of independent variables result in reasonable confidence in the feasibility of the datasets comparison ${ }^{4}$.

The first survey included in our analysis here, "Quality of Life in the City" (QinCity1 \& QinCity2), is research focusing on the population aged 60 and above in the 14 largest cities of the Czech Republic and covering a range of topics such as housing, mobility, neighbours, activities, and perceptions of changes to physical space, etc. QinCity2 used the same demographic and similar topics, but data were collected only in the three largest Czech cities (Prague, Brno and Ostrava). Again, similar issues were explored in the older populations of small towns and rural areas in the RURAL Survey (2016). The fourth, the Role Overload Survey (2014), was limited to respondents aged 5070 and focused on the issue of having a wide range of social roles in later life, with an emphasis on the role of grandparent. The Ageism 2007 survey used a questionnaire to determine the perception and prevalence of age discrimination in different areas of social life among the 18+ adult population; some aspects of age salience were also monitored. In 2012, the survey was repeated on a new set of respondents. The Consumption and Consumers in Higher Age (2011) research project looked at the adult population aged 40 and above and surveyed a wide range of topics relating to income and expenditure, shopping attitudes

\footnotetext{
4 In many aspects, the high standardisation of interview tools and situations is taken as a basic rule in the quantitative methodologies, which is believed to lead to full comparability of datasets also across nations and societies. In our study we choose to employ multi-level modelling to cover for any differences there may be between the surveys we compare. As we will show later, the surveys differ, but differences are small and show similar trends. Therefore, we believe their comparability is not corrupted.
} 
and behaviour, as well as experience with scammers and various unfair business practices.

Data from all seven surveys were combined and cleaned of respondents under the age of 60 , who were present in some data sets. This cut of was chosen arbitrarily to include maximum cases possible. The resulting data set had 5,190 respondents, of which $43 \%$ were men and $57 \%$ were women. Approximately $11 \%$ of respondents were university graduates, $25 \%$ had completed secondary education, while $41 \%$ had completed vocational training. In the Czech Republic, the bachelor's degree in education was extended only after the year 2000, so it was not relevant for persons over 60 years with respect to distinguishing between individual degrees of tertiary education ${ }^{5}$. As we analysed both the characteristics of the interviewer and the interviewee, we found it interesting that only $26 \%$ of the interviewers in the resulting data set were men; the average age of both sexes combined was 47 years. Information on interviewer education was not available in individual surveys. The basic characteristics of the resulting data set are summarized in Table 1.

Table 1: Characteristics of data files used

\begin{tabular}{lcccccc}
\hline Data Files & & \multicolumn{3}{c}{ Respondents } & \multicolumn{2}{c}{ Interviewers } \\
\hline Name & N & $\begin{array}{c}\text { Share } \\
\text { of Women }\end{array}$ & $\begin{array}{c}\text { Share of } \\
\text { Tertiary } \\
\text { Educated }\end{array}$ & $\begin{array}{c}\text { Mean of } \\
\text { Age }\end{array}$ & $\begin{array}{c}\text { Share of } \\
\text { Women }\end{array}$ & $\begin{array}{c}\text { Mean of } \\
\text { Age }\end{array}$ \\
\hline QinCity1 & 1,001 & $58.14 \%$ & $12.11 \%$ & 69.58 & 70.83 & 51.41 \\
QinCity2 & 921 & $59.72 \%$ & $15.53 \%$ & 70.72 & 82.63 & 41.60 \\
Ageism 2007 & 578 & $61.07 \%$ & $7.44 \%$ & 68.79 & 55.02 & 53.40 \\
Ageism 2012 & 419 & $48.21 \%$ & $13.37 \%$ & 67.76 & 79.24 & 41.22 \\
RURAL & 1,244 & $56.09 \%$ & $4.28 \%$ & 70.42 & 74.74 & 49.54 \\
Consumers & 667 & $56.52 \%$ & $13.64 \%$ & 69.90 & 79.76 & 43.09 \\
Role overload & 360 & $53.06 \%$ & $12.22 \%$ & 64.68 & 78.89 & 44.47 \\
Total & 5,190 & $56.89 \%$ & $10.63 \%$ & 69.45 & 74.48 & 47.07 \\
\hline
\end{tabular}

Due to the differences in the number of sub-data sources and their number, it was statistically appropriate to use multi-level regression model, although simple one-level logistic regression model gave the same results. The dependent variable for hypotheses $\mathrm{H} 1-\mathrm{H} 5$ was the perceived and recorded difficulty of filling in the questionnaire. This was evaluated by the interviewer, who used a four-level scale indicating whether the cooperation with a particular respondent was for him/her very simple, quite simple, quite demanding, or very demanding. The average of perceived difficulty was 2.25 , i.e. "fairly simple".

\footnotetext{
5 The ethnicity was not followed by the surveys here. In Czech context, the Roma, Vietnamese or Ukrainian are among the most populous ethnic minorities, however, they are very difficult to reach by standard survey methodologies, especially due to limited information about their basic distribution in the population.
} 
In general, $19 \%$ of interviewers considered interviewing people in higher age very simple, $44 \%$ fairly simple, $30 \%$ rather demanding, $7 \%$ as very demanding. All dependent variables were conceived as linear; and the independent variable was considered to be continuous. We are aware of the statistical constraints this step imposes, but due to the differences in the individual data sets it is more important to use multi-level modelling even with shorter scale of the dependent variable than to use logistic regression, which is statistically more correct but much more difficult to compute and interpret. Therefore, multi-level linear regression was chosen as an analytical tool.

As independent variables, the basic characteristics of the respondent were used in the final model - gender, age, and education (encoded in four grades: basic and unfinished, secondary without state school leaving exam ("maturita"), secondary with the "maturita" exam, and tertiary). We used two subjective variables to test in the model: subjective age (five values: young, middle age, higher middle age, older, old) and morale (decimal numbers ranging from 1 to 3 ). The morale scale was inspired by the Philadelphia Geriatric Center Morale Scale (Lawton 1975), in which morale is a multidimensional concept defined as the level of future-oriented optimism or pessimism regarding the problems and opportunities associated with aging. This scale was calculated as the arithmetic average of responses to three questions in which the respondent evaluated whether he or s/he had more, the same, or less appetite for life; whether s/he felt the same, less, or more useful with increasing age; and whether s/he was more or less (or to the same extent) happy compared to his/her level of happiness at a younger age. The dualism of optimistic - pessimistic variants was enhanced by the neutral variant in order to make the scale more age friendly, as suggested by Carp (1989).

The morale scale was available in all data sources except the Consumers survey. For this data set, morale was imputed as the average value of morale from the other data sets, this calculated for each combination of education and respondent's age. It was with these variables that the morale scale in the other datasets was most closely correlated. The respondent's characteristics were also supplemented by an indicator of his/her health status as a control. Subjective health status was coded on a scale of 1 to 10 with higher values indicating more severe health issues. Other independent variables used in regression model were the characteristics of interviewers, namely their age and gender. More information, such as an interviewer's level of education, was unfortunately not available in data sources. With respect to the $\mathrm{H} 2$ hypothesis, an interaction between the gender of the interviewer and the gender of the respondent were added to the model. As the last independent variable, the difference between age of the interviewer and the age of the respondent was used. 


\section{Results}

The estimated coefficients of the final regression model are summarized in Table 2. In the model, we investigated how the characteristics of respondents and interviewers influenced the difficulty of co-operation as perceived by interviewers. It turned out that the age of interviewers increases the perceived difficulty only slightly if we control for the influence of other variables, such as the gender of the interviewer and the respondent's age and education. On the other hand, the regression coefficient shows a change on the scale of the perceived difficulty of filling in the questionnaire that occurs when the age increases by one year. Therefore, the coefficient needs to be multiplied by the age of the interviewer. Since the coefficient is positive (0.009), we can say that with the increasing age of the interviewer, the perceived difficulty of filling in the questionnaire increases (as shown, for example, in Figure 1 and Figure 3). Therefore, Hypothesis H1 (the hypothesis of the experienced interviewer) must be rejected.

For the hypothesis of homogeneity (H2) we estimated the marginal effects of the influence of the interviewer's gender and the respondent's gender at the different respondents' age. Marginal effects show the change in the dependent variable as a function of changes in the independently chosen variable (or variables) if all other variables are kept constant. This allows us to clearly see the refined influence of a specific independent variable on a dependent variable. In our case, which is shown in Figure 1, we can see how the interviewer perceives the difficulty of filling in the questionnaire according to the sex of the interviewer (first value in the legend) and the sex of the respondent (second value in the legend), while the other variables (e.g. age of both respondent and interviewer, respondent's education, ...) are kept constant. It turns out that the interviewer's perception of the difficulty of filling in the questionnaire increases along with the age of the respondent. Male interrogators who fill in a questionnaire with a female respondent perceive the highest difficulty (age of both being held constant). At a great distance follow male interviewers interviewing male respondents. Next, there are women interviewers, who perceive almost the same level of difficulty regardless of whether they interview men or women. The H2 hypothesis assumes that interviewers of the same sex as their respondents would perceive less difficulty. In Figure 1, we see that a man interviewing another man perceives less difficulty than a man interviewing a woman, and that a woman interviewing a woman perceives less difficultly than a woman interviewing a man. But the difference in the case of female interviewers is almost insignificant. The difference in recorded difficulty in extreme points (female - female vs. male female) was approx. 0.15 points on a 4 -points scale, which represents $4 \%$. 
With some license and generalisation, we can argue that a $4 \%$ difference between female and male interviewers is rather small for practical considerations. However, we cannot reject hypothesis $\mathrm{H} 2$.

Table 2: Influence of respondent and interviewer characteristics on perceived interview difficulty (significance in parentheses)

\begin{tabular}{lll}
\hline & & Difficulty \\
\hline Respondent & & $0.009(0.004)$ \\
Age & Male & Ref. \\
Sex & Female & $0.048(0.267)$ \\
& Primary & Ref. \\
Education & Vocational & $-0.164(0.000)$ \\
& Secondary & $-0.222(0.000)$ \\
& Tertiary & $-0.358(0.000)$ \\
Subjective Age & & $0.076(0.000)$ \\
Morale & & $-0.165(0.000)$ \\
Health & & $0.057(0.000)$ \\
\hline Interviewer & & \\
Age & & $0.001(0.757)$ \\
Sex & Male & Ref. \\
& Female & $-0.047(0.225)$ \\
\hline Interaction & & \\
Resp. Sex vs. Int. Sex & Male, Male & Ref. \\
Age difference & Female, Female & $-0.081(0.110)$ \\
\hline Constant & & $-0.001(0.868)$ \\
\hline Model & & $1.506(0.000)$ \\
N observations & & \\
N groups & & 5,014 \\
ICC & & 7 \\
\hline & & 0.037 \\
\hline
\end{tabular}

The hypothesis of the experienced respondent (H3) assumed that respondents with higher levels of education would be less likely to be perceived by interviewers as difficult to interview; that is, interviewers in their case would report less difficulty in completing the questionnaire. The results of the model confirm this hypothesis: compared with basic education, secondary education reduces the perceived interview difficulty by 0.16 points, the obtaining of a school-leaving certificate by 0.22 points, and higher education by 0.36 points. Indeed, with the increasing education of the respondent, the 
perceived difficulty of conducting the interview decreases, so hypothesis of $\mathrm{H} 3$ cannot be rejected.

Figure 1: Combined influence of the interviewer's and respondent's gender on the perceived difficulty of the interview (marginal effects)

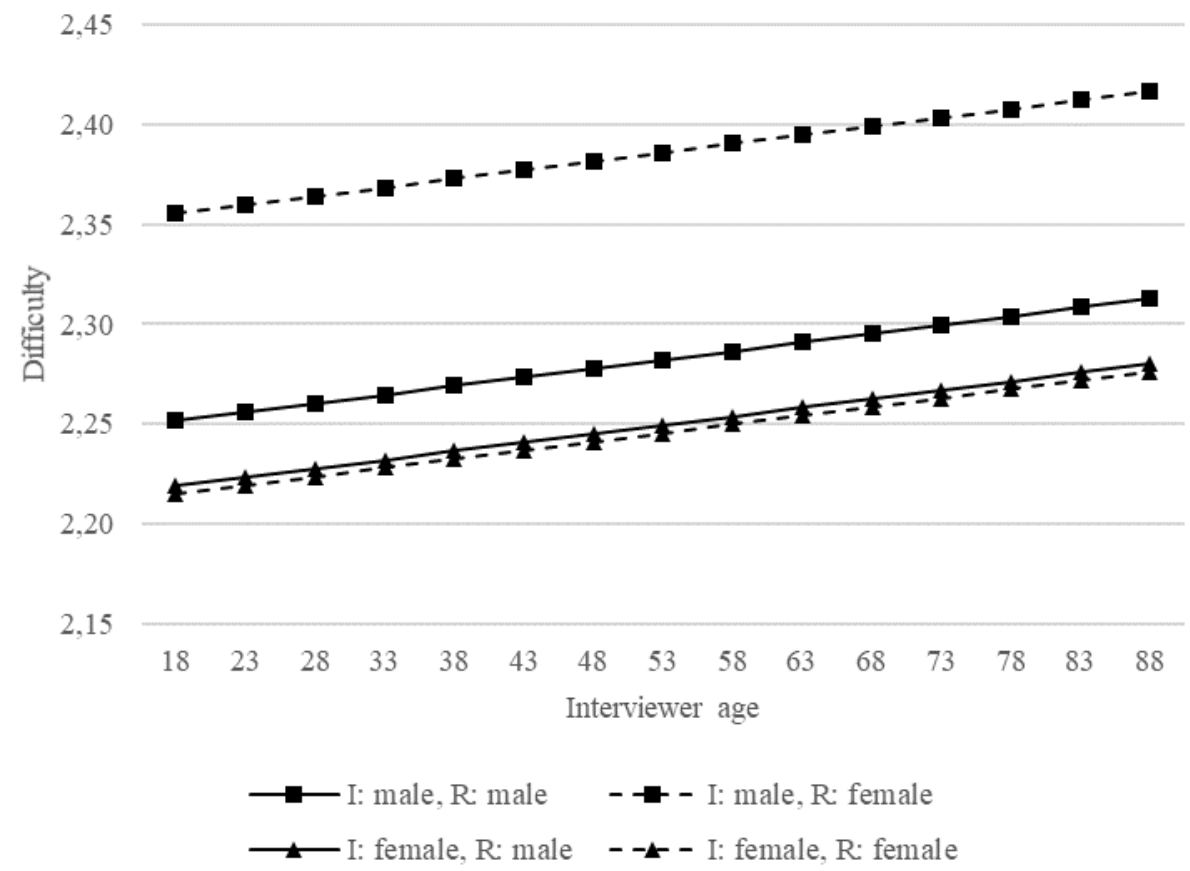

When testing for the differences in age of the interviewer and respondent (see next page, Figure 2) we obtain confirmatory results already given in Figure 1: the younger interviewers (in age more distant from the respondent) report lower difficulties. It may reflect both their higher relative strength/stamina (or less fatigue) and support the hypothesis on the value of intergenerational communication but may also represent additional argument on the difficulties older interviewers may face when facing the issue of aging (e.g. self-stereotypes, etc.). 
Figure 2: Influence of the difference between interviewer's and respondent's age on the perceived difficulty of the interview (marginal effects)

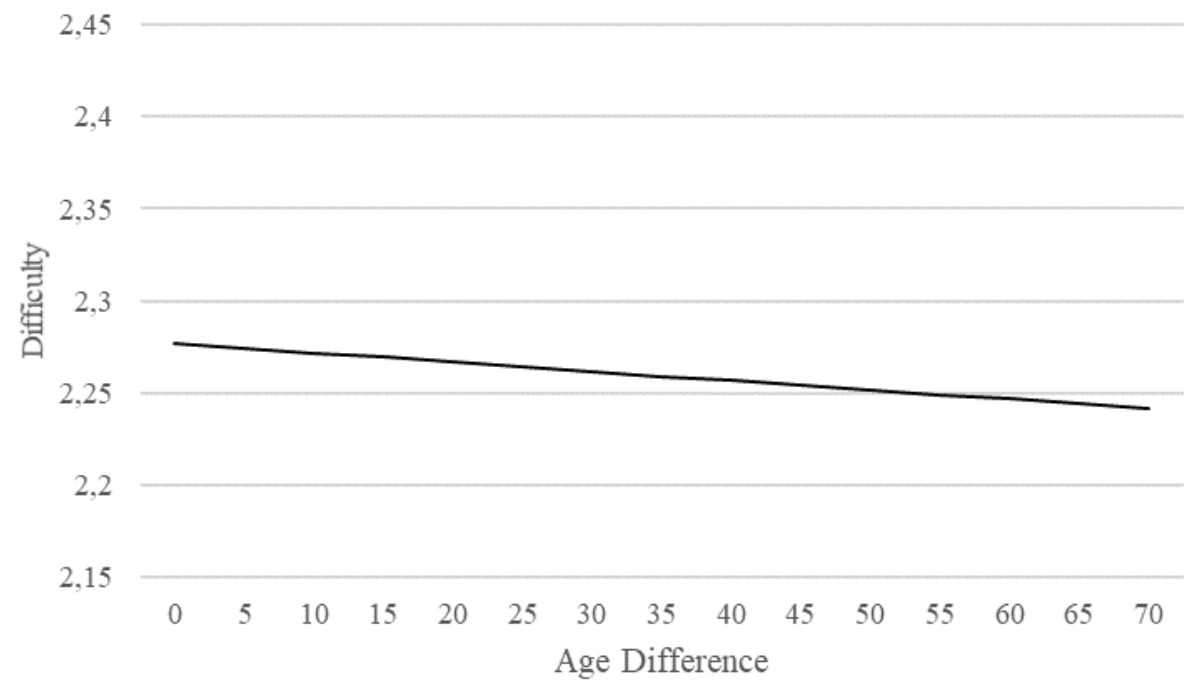

Hypothesis $\mathrm{H} 4$ (the hypothesis of age in disguise) supposes a relationship between morale and the interviewer's perceived difficulty in filling in the questionnaire. The estimated coefficients of the model show that with each unit increase in morale (which is in the range of 1 to 3 ), the perceived difficulty recorded by the interviewer (ranging from 1 to 4 ) decreases by about 0.17 points. More positively aging respondents make the interviews about aging topic easier for interviewers. Therefore, hypothesis $\mathrm{H} 4$ cannot dismissed on the basis of the available data.

Hypothesis H5 assumes that the characteristics of a particular form of research do not interfere with the characteristics of the interviewer with the characteristics of the respondent. On the basis of the results of multi-level regression analysis, we can reject this hypothesis. The characteristics of a specific data source, such as the number of questions, their difficulty, and the average duration of the interview, etc., have a small but clearly demonstrable effect on the interviewer's perceived difficulty of interviewing, as shown in Figure 3. The deviations in this figure show only differences at the level of data sources, not the individual differences that would arise from the characteristics of the respondent or interviewer included in the model (respondent's age, gender, education, subjective age, morale, age and gender of the interviewer). 
However, we are not able to distinguish which characteristics of the data file were the most crucial with respect to this finding. We can only assume that this result can be ascribed, for example, to factors such as the topic of the survey, the complexity of the questions asked, their order, and maybe also the educational level of the interviewer, for which we do not control due to the unavailability of such information. For this article, however, it is important that the interviewer perceived difficulty of filling in the questionnaire with a particular respondent is not solely based on social aspects brought in by the personal characteristics of the interviewer and the respondent, other factors step in too.

Figure 3: The influence of differences in data sources (marginal effects)

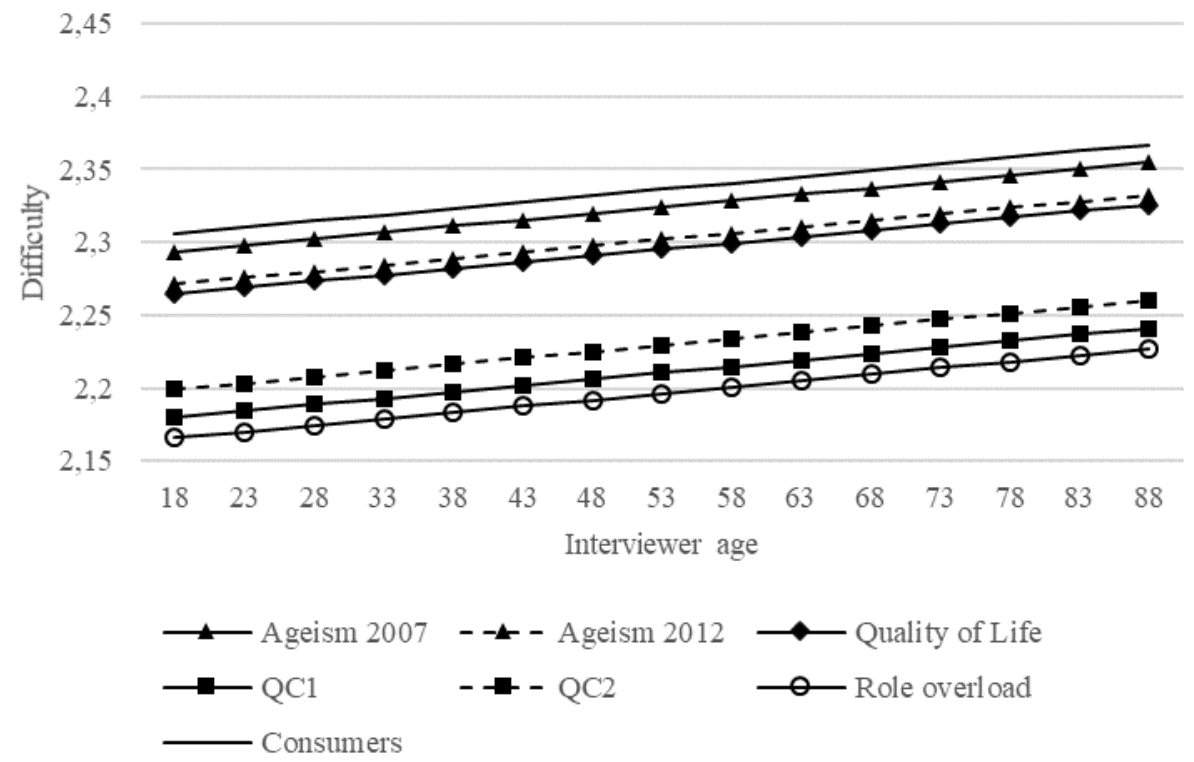

To answer the main research question "What aspects affect the quality of cooperation with various types of older respondents?", we conducted a secondary analysis of data from seven research projects focusing on older persons in the Czech Republic. We formulated five hypotheses that predicted a connection between 1) the characteristics of the interviewer, 2) the characteristics of the respondent, including his/her subjective age and morale, as an indicator of future oriented optimism vis-à-vis aging processes with a 
potential influence on the course of surveying aging-related topics, and 3) the interviewer's perceived difficulty in conducting the research interview.

It turns out that this connection exists. The higher age of the respondent and the higher age of the interviewer are associated with an increase in the perceived difficulty of the interviewing process on the part of the interviewer. In contrast, higher morale as well as higher education on the part of the respondent reduce this perceived difficulty. Male interviewers report higher levels of difficulty in interviewing, especially when interviewing women. However, the characteristics of the respondent and the interviewer are not the only determinants of the answers recorded. For example, the characteristics of the research tool, such as the number of questions, their difficulty, the composition of the sample, and perhaps also the subject matter, interfere with the relationship. Further studies should try to disentangle these influences.

\section{Discussion}

Studies dealing with the characteristics of research instruments and/or with interviewer impacts hardly ever take into account the specificity of the variety of older respondents. (But see Arning - Ziefle 2008) More recent methodological texts that deal with research on seniors frequently focus on qualitative methodologies. (Medeiros 2014; Randall et al. 2006; Jamieson Victor 2002; cf. also broader discussion led by Lutherová et al. 2016) In the qualitative research interview, embedded empowering features are present which "transform" the respondent into a partner in the communication process. In a standard survey situation, this ideal communicational symmetry could easily be violated, especially in older respondents. (Minocha et al. 2013) This directs attention to the role of the interviewer, his or her positionality (Sultana 2007) and possible sources of bias brought by him/her into the data. The situation is even more complex in the quantitative research designs, where the researcher, usually in the capacity to reflect and to report on the positionality and the contexts, and the interviewer as a data collector, are two distinct persons.

Using seven different survey datasets, we were able to illustrate the factors that affect the difficulties of interviewing in older samples, and how these are influenced by the gender and age of the interviewer and interviewee. Since all the projects specifically dealt with aging-related issues, including some sensitive and emotionally difficult questions such as experience of different forms of age discrimination, abuse of the elderly, or financial fraud, the selfpresentation of the respondent as a successful, active ager also exercised its statistically significant effect.

There is no general agreement about who should interview older people, as there seem to be too many co-founding variables which in real life situations 
cannot be controlled for. However, knowledge of, and control over the issues that can be addressed in the course of the recruitment and training of interviewers with regard to the collection of data on aging-related topics can lead to more relaxed interviews and more reliable data. Our results do not support the hypothesis that older interviewers can more easily establish a better rapport with older interviewees (homogeneity hypothesis), as the age of the interviewer seems to add to the perceived difficulty of the interview. The average age of the interviewers was slightly below fifty years of age (47 years) so many of the interviewers could also have been respondents in the surveys of people aged 60+. Holding other things constant, this result means that their age may be a proxy for issues typically followed only in older respondents - health issues, fatigue, and problems with (the administration of) complex questions or long scales. If combined with an older respondent on the other side of the table, and/or a difficult topic, this may understandably produce a less favourable evaluation of the interview process as a result.

Although we hesitate to work with gender stereotypes, our results do suggest that women perform better than men as interviewers of older people. In particular, when men interview older women on aging-related issues, they report higher levels of difficulty, which is in line with previous studies. (Durant et al. 2010; Jäckle et al. 2011) Liu and Stainback (2013) found that female interviewers elicited more positive and neutral responses about marriage than negative ones, but insomnia was more often admitted by both sexes to male interviewers (Boyd - Westfall 1965), so the topic as the context of the survey is crucial when considering the selection and training of interviewers with respect to their gender and age. We do not suggest that there should be any age or gender discriminatory selection of interviewers for any particular study, but that age- and gender-sensitive training and supervision when age/gender sensitive topics are to be surveyed is, according to our results here, strongly advisable. Such training should provide and age-friendly tools for interview and communication practices. Similar training is already available for teachers and human-resources experts and geragogy can provide useful resources (cf. Brookfield 2005; Schuetz 1982), especially its critical branch. (Creech Hallam 2015; Brookfield 2005) For example, Findsen and Formosa (2011: 101) in the context of educators, call for educators (or interviewers), in developing clear objectives and strategies for engaging and empowering older learners (or interviewees), 'need to suspend their assumptions about older learners, test their own prejudices, and learn to be more self-critical'. The same applies to doing research with older people.

While recording difficulties in a particular research interview setting does not mean obtaining inferior data, we would expect and argue that the identification of difficulty has its (possibly both subjective and objective) 
reason(s) and that, therefore, there can be an increased risk of (un)recorded mistakes, missing data, unfinished or interrupted interviews, etc., as, for example, described in research on the effects of fatigue. Such effects are, however, mainly available with respect to the interviewee, not so often with respect to the administrator. If we assume that fatigue in an interviewer can be cumulative, a call for serious intervention should follow in order to support the best possible quality, validity, and reliability of data in age/aging studies.

However, not all difficulties recorded by the interviewers should be blamed on their or the respondents' characteristics. The study topic and quality of the questionnaire also plays a role. In this paper, we were not able to analyse objective measures of these seven surveys, as we did not have equal sets of information for each one. Therefore, it would be interesting to follow aspects such as duration of the individual interview, original number of variables, number of open ended questions, share of long scales (Bogner 1996; Burchell Marsh 1992) etc. in future steps. However, when trying to interpret the results obtained in Figure 3, we can speculate that the perceived level of difficulty can be, at least partially, ascribed to the topic and the related sample composition. At the top of the list in descending order of perceived difficulty is the "Consumers survey", which asked many questions on the financial situation of older respondents, including debt and fraud which are regarded as "traditionally" difficult questions. (Matthews et al. 1991; Gibson - Aitkenhead 1983) The following two surveys "Ageism" from 2007 and 2012, look at experience with various types of age discriminatory behaviours, including extreme forms such as the abuse and neglect of the elderly. (Vidovićová 2008) Such questions are always put towards the end of the interview, where questions on paradata are usually also situated.

If internalized age stereotypes and/or some form of gerontophobia (Martens et al. 2006) are at play here, it could explain the validity of hypothesis $\mathrm{H} 4$ - i.e. that interviewees who have higher morale and a positive outlook on the future (and holding other aspects constant), who in some sense disguise their aging in more "middle age" wrappings, make the interview for the interviewer easier. The difference between the 2007 and 2012 Ageism survey evaluations can be interpreted as an effect of the steadily rising awareness of these issues within society. Various policy frameworks of the 2012 European Year for Active Aging and Solidarity between Generations were dedicated to this goal, and public campaigns at that particular time could have had resulted in greater ease of the interviews, as public "talking about aging" has become more visible.

The RURAL and QinCity1 and QinCity2 surveys are comparable with regard to many items, but differ in some. The real difference here, however, could be the sample composition. All three surveys were based on quota selection and were representative of the old age population of interest, i.e. of 
big cities, and small rural municipalities. In the rural sample, there were almost three-times more people with elementary education, and almost three-times fewer people in the highest educational category when compared to the urban sample. As the topics covered in the survey were apparently of great interest to older participants (life quality; perception of, and satisfaction with the surrounding environment; problems encountered; and the potential for change and improvement), the relative difficulties encountered with the RURAL survey can probably be ascribed to the generally less well-educated sample in rural areas. This is in line with the positive results we obtained when testing our third hypothesis on the increasing ease of filling in questionnaires with more educated people. Education can provide better training in functional literacy (Verhoeven 1994) as well as be a proxy for more opportunities to become a subject of sociological surveys. Older people with higher education are, for example, entitled to study at the Universities of the Third Age (also more often based in big cities) and this subpopulation is considered to be a very convenient sample for use in academic and market research. (Villar - Celdrán 2012) As a result, the probability of meeting an experienced survey participant in the city is higher compared to rural areas, and experienced survey participants, as shown by our data (H3) and (Petrová Kafková 2012), can produce better interviews.

The least difficulties were recorded in the Role Overload study. This was part of the project titled "Role overload: grandparents in the era of active aging", which aimed to encompass the experience of older people in various social roles and then look more closely at the activities carried out as part of the grandparenting role. (Vidovićová et al. 2015) As the results of this survey clearly showed that the grandparenting role is the role which brings the greatest positive affect (Hubatková 2017), we can speculate that the topic as such had a positive influence over the course of the interview, supporting the enthusiasm of older participants and their willingness to participate, and, as a result, also made the interviewing easier for the interviewers.

In summary, our present study shows the advantages and disadvantages of following the interviewer effect in individual surveys and in pooled data. Results from different studies should always be interpreted on the basis that the various survey conditions are broadly similar, such conditions including the topic, the technical complexity of the given empirical tool, and the individual demographics of the study subjects and administrators. Our data suggest that while interviewer effects explain relatively little of the variance (Cleary et al. 1981), they cannot be dismissed as having no influence at all.

Lucie Vidovićová is a sociologist. Her research interests include sociology of age, environmental gerontology and active aging. She is also involved in the 
research projects in the field of family and social policy. She also cooperates with different governmental and NGO bodies in the field of senior advocacy.

Tomáš Doseděl studied computer science at the Brno University of Technology and sociology at Masaryk University. Currently he is a PhD student of sociology. His research interests include higher education and labor market issues.

\section{REFERENCES}

ARNING, K. - ZIEFLE, M., 2008: Development and Validation of a Computer Expertise Questionnaire for Older Adults. Behaviour \& Information Technology, 27(1), 89-93. https://doi.org/10.1080/01449290701760633

BENNEY, M. - RIESMAN, D. - STAR, S. A., 1956: Age and Sex in the Interview. American Journal of Sociology, 62(2), 143-152.

BOGNER, K., 1996: The Effect of Questionnaire Length on Response Rates A Review of the Literature. (online) Proceedings of the Section on Survey Research Methods, Alexandria, VA: American Statistical Association, pp. 1020-1025. Accessed: 13.11.2017. Available from: www.census.gov/srd/papers/pdf/kb9601.pdf

BOYD, H. W. - WESTFALL, R., 1965: Interview Bias Revisited. Journal of Marketing Research, 2(1), 58-63.

BROOKFIELD, S., 2005: The Power of Critical Theory for Adult Learning and Teaching. Maidenhead: Open University ress.

BURCHELL, B. - MARSH, C., 1992: The Effect of Questionnaire Length on Survey Response. Quality and Quantity, 26(3), 233-244. https://doi.org/10.1007/BF00172427

CARP, F. M., 1989: Maximizing Data Quality in Community Studies of Older People. In: Lawton, P. M. - Herzog, A. R.: Special Research Method for Gerontology. Amityville: Baywood Publishing; 93-122.

CLEARY, P. D. - MECHANIC, D. - WEISS, N., 1981: The Effect of Interviewer Characteristics on Responses to a Mental Health Interview. Journal of Health and Social Behavior, 22(2), 183-193.

CREECH, A. - HALLAM, S., 2015: Critical Geragogy: A Framework for Facilitating Older Learners in Community Music. London Review of Education, 13(1), 43-57.

DAVIS, R. E. - COUPER, M. P. - JANZ, N. K. - CALDWELL, C. H. - RESNICOW, K., 2010: Interviewer Effects in Public Health Surveys. Health Education Research, 25(1), 14-26. https://doi.org/10.1093/her/cyp046

DERRETT, S. - COLHOUN, S., 2011: Being a Quantitative Interviewer: Qualitatively Exploring Interviewers' Experiences in a Longitudinal Cohort Study. BMC Medical Research Methodology, 11, 165. https://doi.org/10.1186/1471-2288-11-165

DURRANT, G. B. - GROVES, R. M. - STAETSKY, L. - STEELE, F., 2010: Effects of Interviewer Attitudes and Behaviors on Refusal in Household Surveys. Public Opinion Quarterly, 74(1), 1-36.

FINDSEN, B. - FORMOSA, M., 2011: Lifelong Learning in Later Life: A handbook on older adult learning. Rotterdam: Sense Publishers. 
FREEMAN, J. - BUTLER, E. W., 1976: Some Sources of Interviewer Variance in Surveys. Public Opinion Quarterly, 40(1), 79-91. http://dx.doi.org/10.1086/268269

GARBARSKI, D. - SCHAEFFER, N. C. - DYKEMA, J., 2016: Interviewing Practices, Conversational Practices, and Rapport: Responsiveness and Engagement in the Standardized Survey Interview. Sociological Methodology, 46(1), 1-38. https://doi.org/10.1177/0081175016637890

GHANE, S. - KOLK, A. M. - EMMELKAMP, P. M. G., 2010: Assessment of Explanatory Models of Mental Illness: Effects of Patient and Interviewer Characteristics. Social Psychiatry \& Psychiatric Epidemiology, 45(2), 175-182. https://doi.org/10.1007/s00127-009-0053-1

GIBSON, D. M. - AITKENHEAD, W., 1983: The Elderly Respondent Experiences from a Large-Scale Survey of the Aged. Research on Aging, 5(2), 283-296.

GOUDY, W. J. - POTTER, H. R., 1975: Interview Rapport: Demise of a Concept. Public Opinion Quarterly 39, 4, 529-543.

GREENBERG, J. - SCHIMEL, J. - MARTENS, A., 2004: Ageism: Denying the Face of the Future. Pp. 28-48 In: Nelson, T. D. (ed.): Ageism: Stereotyping and Prejudice Against Older Persons. MIT Press.

GROVES, R. M. - CIALDINI, R. B. - COUPER, M. P., 1992: Understanding the Decision to Participate in a Survey. The Public Opinion Quarterly, (4), 475.

HALL, S. - LONGHURST, S. - HIGGINSON, I. J., 2009: Challenges to Conducting Research with Older People Living in Nursing Homes. BMC Geriatrics 9, 38. https://doi.org/10.1186/1471-2318-9-38

HESS-WIKTOR, K. - OPOCZYŃSKA, M., 2012: Why is Research Involving People with Alzheimer's Disease Difficult? Archives of Psychiatry \& Psychotherapy, 14(2), 41-47.

HUBATKOVÁ, B., 2017: Number of Roles and Well-Being Among Older Adults in the Czech Republic International Journal of Aging and Later Life, Advance access, doi: 10.3384/ijal.1652-8670.16-323

HUDDY, L. - BILLIG, J. - BRACCIODIETA, J. - HOEFFLER, L. - MOYNIHAN, P. J. - PUGLIANI, P., 1997: The Effect of Interviewer Gender on the Survey Response. Political Behavior, 19(3), 197-220. https://doi.org/10.1023/A:1024882714254

HYMAN, H. H., 1954: Interviewing in Social Research. Chicago: University Press.

ISAKSSON, U. - SANTAMÄKI-FISCHER, R. - NYGREN, B. - LUNDMAN, B. ÅSTRÖM, S., 2007: Supporting the Very Old When Completing a Questionnaire Risking Bias or Gaining Valid Results? Research on Aging, 29(6), 576-589.

JAMIESON, A. - VICTOR, C., 2002: Researching Aging and Later Life. The Practice of Social Gerontology. Buckingham: Open University Press.

JÄCKLE, A. - LYNN, P. - SINIBALDI, J. - TIPPING, S., 2011: The Effect of Interviewer Personality, Skills and Attitudes on Respondent Co-Operation with Face-to-Face Surveys (Working Paper No. 2011-14). ISER Working Paper Series. Retrieved from https://www.econstor.eu/handle/10419/65915

JOHNSON, T. P. - MOORE, R. W., 1993: Gender Interactions Between Interviewer and Survey Respondents: Issues of Pornography and Community Standards. Sex Roles, 28(5-6), 243-261. 
JOHNSON, W. T. - DELAMATER, J. D., 1976: Response Effects in Sex Surveys. Public Opinion Quarterly, 40(2), 165-181.

KUSUMASTUTI, S. - VAN FENEMA, E. - POLMAN-VAN STRATUM, E. C. F. ACHTERBERG, W. - LINDENBERG, J. - WESTENDORP, R. G. J., 2017: When Contact Is Not Enough: Affecting First Year Medical Students' Image towards Older Persons. PLOS ONE, 12, e0169977. https://doi.org/10.1371/journal.pone.0169977

LAWTON, M. P., 1975: The Philadelphia Geriatric Center Morale Scale: A Revision. Journal of Gerontology, 30(1), 85.

LIU, M. - STAINBACK, K., 2013: Interviewer Gender Effects on Survey Responses to Marriage-Related Questions. Public Opinion Quarterly, 77(3), 606-618. https://doi.org/10.1093/poq/nft019

LUTHEROVÁ, G. - HLINČÍKOVÁ, M. - VOLANSKÁ, L., 2016: Aktuálne metodologické prístupy a témy v etnologickom/antropologickom bádaní. Slovenský národopis/Slovak ethnology, 64(3), 268-270.

MARTENS, A. - JOHNS, M. - GREENBERG, J. - SCHIMEL, J., 2006: Combating Stereotype Threat: The Effect of Self-Affirmation on Women's Intellectual Performance. Journal of Experimental Social Psychology, 46, 236-243. http://dx.doi.org/10.1016/j.jesp.2005.04.010

MATTHEWS, A. M. - ROSS, L. R. - COUSINEAU, A. E. G., 1991: Obtaining Income Information from Elderly Respondents: An Assessment of Non-Response and Reliability. Canadian Journal on Aging / La Revue Canadienne Du Vieillissement, 10(2), 177-198. https://doi.org/10.1017/S0714980800005237

MEDEIROS, K. de. 2014: Narrative Gerontology in Research and Practice. Springer. ISBN 978-0-8261-9937-9.

MINOCHA, S. - HARRNETT, E. - DUNN, K. - EVANS, S. - HEAP, T. - MIDDUP, C. P. - MURPHY, B. - ROBERTS, D., 2013: Conducting Empirical Research with Older People. (online). Centre for Research in Computing, The Open University. Available from:

https://openlab.ncl.ac.uk/vulnerability/files/2013/03/Minocha_DFWVP2013.pdf. Accessed: 13.11.2017.

PEEL, N. M. - WILSON, C., 2008: Frail Older People as Participants in Research. Educational Gerontology, 34(5), 407-417. https://doi.org/10.1080/03601270701835973

PETROVÁ KAFKOVÁ, M., 2012: Vliv věku a pohlaví tazatele a respondenta na náročnost výběrového šetření $v$ seniorské populace. [The Influence of Age and Gender of Interviewer and Respondent's Characteristics on the Difficulty of Responding to Sample Surveys Among the Elderly Population.] Data a výzkum SDA Info, 6 (2): 113-127.

RANDALL, W. - PRIOR, S. - SKARBORN, M., 2006: How Listeners Shape what Tellers Tell: Patterns of Interaction in Lifestory Interviews and their Impact on Reminiscence by Elderly Interviewees. Journal of Aging Studies, 20, 4, 381-396. https://doi.org/10.1016/j.jaging.2005.11.005. 
RECOMMENDATIONS on Aging-Related Statistics, 2016: The Task Force on Agingrelated Statistics. UNECE. New York, Geneva: United Nations. ISBN 978-92-1117119-8.

RODGERS, W. - HERZOG, R., 1995: Collecting Data about Oldest Old: Problems and Procedures. Pp. 135 -156. In: Suzman, R. M. - Willis, D. P. - Manton, K. G.: The Oldest Old. Oxford University Press.

SMIT, J. H. - DEEG, D. J. - SCHMAND, B. A., 1997: Asking the Age Question in Elderly Populations: a Reverse Record Check Study. The Journals of Gerontology. Series B, Psychological Sciences and Social Sciences, 52(4), 175-177.

SCHUETZ, J., 1982: Geragogy: Instructional Programs for Elders. Communication Education, 31(4), 339-347. https://doi.org/10.1080/0363458209384702

SUlTANA, F., 2007: Reflexivity, Positionality and Participatory Ethics; Negotiating Fieldwork Dilemmas in International Research. ACME: An International E-Journal for critical geographies 6(3): 374-385.

VERCRUYSSEN, A. - WUYTS, C. - LOOSVELDT, G., 2017: The Effect of Sociodemographic (Mis)Match between Interviewers and Respondents on Unit and Item Nonresponse in Belgium. Social Science Research, 67(Supplement C), 229-238. https://doi.org/10.1016/j.ssresearch.2017.02.007

VERHOEVEN, L., 1994: Modelling and Promoting Functional Literacy. Pp. 3-34. In: Verhoeven, L. (ed.): Functional Literacy. Theoretical Issues and Educational Implications. Amsterdam/Philadelphia: John Benjamin's Publishing Company.

VIDOVIĆOVÁ, L., 2008: Stárnutí, věk a diskriminace - nové souvislosti. Brno: Masarykova Univerzita.

VIDOVIĆOVÁ, L. - GALČANOVÁ, L. - PETROVÁ KAFKOVÁ, M., 2015: Význam a obsah prarodičovské role u mladých českých seniorů a seniorek. Sociologický časopis / Czech Sociological Review, 51 (5): 761-782. ISSN 0038-0288. doi:10.13060/00380288.2015.51.5.213.

VILLAR, F. - CELDRÁN, M., 2012: Generativity in Older Age: A Challenge for Universities of the Third Age (U3A). Educational Gerontology, 38(10), 666-677. DOI: 10.1080/03601277.2011.595347.

VRIES, K. de - LEPPA, C. J. - SANDFORD, R. - VYDELINGUM, V., 2014: Administering Questionnaires to Older People: Rigid Adherence to Protocol May Deny and Disacknowledge Emotional Expression. Journal of Aging Studies, 31, 132-138. https://doi.org/10.1016/j.jaging.2014.09.005

WEIL, J., 2015: Applying Research Methods to a Gerontological Population: Matching Data Collection to Characteristics of Older Persons. Educational Gerontology, 41(10), 723-742. https://doi.org/10.1080/03601277.2015.1048172

WEIL, J., 2017: Research Design in Aging and Social Gerontology: Quantitative, Qualitative, and Mixed Methods. New York: Taylor \& Francis.

WHITE, E. M., 2001: Attitudes of Preschool Children Toward the Elderly at the Stride Rite Intergenerational Day Care Center (ed.): University of Massachusetts Amherst, United States - Massachusetts. Retrieved from https://search.proquest.com/docview/230811682/citation/412935E8CCF04DFCPQ/1.

WILLARD, R. - HERZOG, R., 1995: Collecting Data about Oldest Old: Problems and Procedures. Pp. 135-156. In: Suzman, R. M. - Willis, D. P.: The Oldest Old. Oxford: Oxford University Press. 